NASA TECHNICAL MEMORANDUM

by Dudley G. McConnell

Lewis Research Center

Cleveland, Ohio

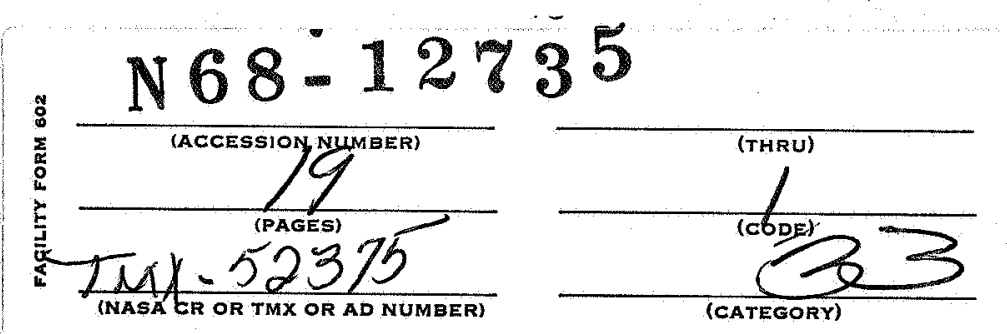

TECHNICAL PAPER proposed for presentation at Engineering Colloquium at the University of Kentucky

- Lexington, Kentucky, November 30, 1967 


\section{RADIANT ENERGY TRANSPORT IN CRYOGENIC CONDENSATES}

by Dudley G. McConnell

Lewis Research Center

Cleveland, Ohio

TECHNICAL PAPER proposed for presentation at Engineering Colloquium at the University of Kentucky

Lexington, Kentucky, November 30, 1967

NATIONAL AERONAUTICS AND SPACE ADMINISTRATION 


\section{RADIANT ENERGY TRANSPORT IN CRYOGENIC CONDENSATES}

by Dudley G. McConnell

Lewis Research Center

National Aeronautics and Space Administration

Cleveland, Ohio

\section{INTTRODUCTION}

Current interest in cryodeposit radiative properties arose in connection with the design of solar space simulators. The question was whether the black background of space could be duplicated in the simulator in spite of the presence of cryosorbed gases on the simulator walls. Cunningham and Young [1] and Caren, et al [2], among others, studied this question experimentally for the cases of $\mathrm{CO}_{2}$ and $\mathrm{H}_{2} \mathrm{O}$ deposits. They found that cryodeposit layers did not appreciably increase the reflectance of black surfaces. Therefore simulation was possible. In addition, they found that deposits did increase the absorptance of highly reflecting surfaces. Thus the presence of a deposit could alter the efficiency of a thermal control system using reflective surfaces.

$0^{\prime}$ Keefe's explanation of the Glenn. Effect provides further motivation for studying the radiative properties of cryodeposits. To review: during the flight of MA-7, Astronaut Col. John Glenn [3] reported seeing "fireflies" just before sunrise on each of his three orbits. These luminous space particles were also reported by Astronauts Carpenter [4] and Cooper [5]. O'Keefe [3, 5] suggested that these particles were crystallized steam. The steam came from the water in Mercury capsule life support system. The cooling water was simply vented to space; and upon passage through the venting ports, the water vaporized, then part crystallized. Indeed, Cooper was able to see the luminous space particles coming from an attitude control thrustor. The thrustor used hydrogen peroxide which forms $\mathrm{H}_{2} \mathrm{O}$ and $\mathrm{O}_{2}$. More importantly, Carpenter reported a profusion 
of particles after rapping his craft's bulkhead. This showed that the space particles could accrete upon a surface in vacuum. Therefore accretion may even occur upon a thermal control surface such as a shadow shield or cryogenic fuel tank.

As a numerical example; figure 1 shows the effect of the presence of an $\mathrm{H}_{2} \mathrm{O}$ deposit on the heat flux through a shadow shield array. Shadow shields are planned mainly to protect cryogenic storage vessels during the interplanetary portion of a mission. At that time, parallel solar radiation is the main source of heat to the cryoreservir. The cryoreservoir is placed within the shadow of the shield array so that the array acts as a barrier to the solar flux. But the shield itself radiates to the cryosurface, so there is some heat flux. In cases 2 and 3 of figure 1 , a deposit forms on the cryosurface and on the inner shield. If the deposit increases the surface absorptance from 0.045 to 0.090 , the flux to the cryosurface also doubles.

In the analysis below, I consider case 2 , the deposit on the cryosurface, in greater detail. I will show that the flux may increase by much more than a factor of two in the presence of a deposit.

Finally, what are sources of cryodeposits. Any material exhausted to space such as auxiliary thrustors, can be a source. N. T. Grier is presently studying backstreaming to the hull from a rocket plume. Furthermore, the spacecraft system may outgas. R. J. Leite* has observed significant outgassing from the multi-layer foil thermal shield on OGO-2. Even after six months in orbit, mass spectrometer reading showed $10^{7}$ particles per cubic centimeter of $\mathrm{H}_{2} \mathrm{O}$ vapor in the vicinity of the instrument package. This is several orders of magnitude

\footnotetext{
*University of Michigan; private communication.
} 
higher than expected in orbit. Over a six-month period, this outgassed vapor could produce an appreciable deposit on a cryogenically cooled instrument surface.

In addition to aerospace interest in cryodeposits, there is also basic interest in the fields of meteorology and astrophysics. In the first case, the noctilucent clouds are thought to be crystalized water vapor. These clouds and their ability to receive solar heat enter directly into the heat budget of our upper atmosphere (say 30 to $60 \mathrm{~km}$ ). Lower level, vapor-crystal clouds effect visual sightings from orbit or from a distance. A classification of planetary signatures would be useful in identifying terrain features through haze and light cloud cover.

In the astrophysical context, F. O. Rice [6, 7] suggests that the alternate light and dark bands on Jupiter result from frozen radical phosphoresence. This phophoresence has been observed in the laboratory [8]; and at low temperatures, the frozen radicals are known to persist for long times. Rice feels that ammonia and/or methane crystals absorb solar energy and liberate free radicals. Because of the low temperature environment, the radicals are long lived: Under the action of the high gravity field and strong atmospheric currents the radicals are convected to the lower levels of the Jovian atmosphere and into the band configuration.

It is interesting to note that the long-lived radiation from $\mathbb{N H}_{2}$ radicals is pale blue in color. This is strikingly similar to the pale bluish glow from the Lewis simulator observed by R. D. Sommers and J. D. Cassidy. The Lewis simulator cryopumps nitrogen and hydrogen. 
In summary, there is widespread interest in cryodeposits and ample motivation for studying radiative transport in cryodeposits.

\section{AITALYSIS}

For a specific configuration to study, consider the case of an $\mathrm{H}_{2} \mathrm{O}$ deposit on the outside wall of a liquid hydrogen fuel tank as shown in figure 2. Initially the deposit, the substrate, and the cryogen are in a quiescent steady-state condition. Then at time zero external radiation from an extended, diffuse, thermal source begins to fall on the deposit. For example, the craft may emerge from the night side of its orbit so that solar radiation may fall on a shadow shield array. The most inboard shadow shield then radiates to the deposit. The object is to find the change in the frost's temperature distribution to determine the heat transferred to the cryogen by conduction in addition to the radiation transmitted through the deposit.

An energy balance for a typical volume element lead to the heat equation in the form

$$
\rho c_{p} \frac{\partial T}{\partial t}=\frac{\partial^{2} T}{\partial y^{2}}+\left\{\begin{array}{l}
\text { amount of } \\
\text { external } \\
\text { flux } a b- \\
\text { sorbed }
\end{array}\right\}-\left\{\begin{array}{l}
\text { amount of } \\
\text { emitted flux } \\
\text { less internal } \\
\text { flux absorbed }
\end{array}\right\}
$$

and the boundary conditions

$$
\begin{aligned}
& T=T_{c} \text { at } y=0 \quad \text { interior interface } \\
& \mathrm{k}\left(\frac{\partial \mathrm{T}}{\partial \mathrm{y}}\right)=\dot{\mathrm{m}} \mathrm{L}_{\mathrm{s}} \text { at } \mathrm{y}=\mathrm{H} \quad \text { exterior interface }
\end{aligned}
$$

The radiation terms thus enter the equation as time-independent, distributed. source terms. Following Gardon, [9], the external flux absorbed in a unit volume is 


$$
\left(\frac{\delta Q}{\delta V}\right)=2 \pi r n^{2} \tau^{\prime}(\alpha) I_{n} \int_{0}^{\beta^{\prime}(\alpha)} e^{-\left(\frac{r y^{\prime}}{\cos \beta}\right)} \sin \beta d \beta
$$

where $y^{l}$ is the depth into the frost and $\beta$ is the angle of refraction of an entering ray. For a geometrically smooth dielectric material, the limiting angle of refraction, $\beta^{I}(\alpha)$, is given by Snell's law. In that case, the energy aibsorbed.

$$
\begin{gathered}
\left(\frac{\delta Q}{r V}\right)=2 t\left[r n^{2} \tau^{1}(\alpha) I_{n}\right]\left\{e^{-r y}+r y \mathcal{E}_{i}(-r y)\right] \\
\left.-\frac{\sqrt{n^{2}-1}}{n}\left[-\frac{n r y}{\sqrt{n^{2}-1}}+\frac{n \gamma y}{\sqrt{n^{2}-1}} \varepsilon_{i}\left(\frac{n r y}{\sqrt{n^{2}-1}}\right)\right]\right\}
\end{gathered}
$$

Hallett and Mason, [10], have studied the growth of ice crystals from a supercooled vapor. Figures 3 and 4 show two forms of ice crystal. These figures show that Snell's law does not apply to the frost surface as a whole. However, Caren, et al. [2], Keegan and Weidner [11], and McCulloch [12] have published data from which an estimate of the surface transmittance can be made-at least for $\mathrm{H}_{2} \mathrm{O}$ and $\mathrm{CO}_{2}$ deposits. Using such an estimate, the external flux term becomes

$$
\begin{gathered}
\left(\frac{\delta Q}{\delta V}\right)=2 r\left(1-\rho_{12}\right) \sigma T_{B B} 4\left[e^{-r y^{I}}+r y \dot{\ell}(-r y)\right] \\
\equiv 2 r\left(1-\rho_{12}\right) \sigma T_{B B}^{4} F\left(r y^{I}\right)
\end{gathered}
$$

This says that by some unspecified process, an amount of radiation of intensity. $\left(1-\rho_{12}\right) \sigma \mathrm{T}_{\mathrm{BB}}^{4}$ crosses the surface of the frost; then the intensity decreases through the frost according to the term in brackets, $F(r y)$. 
By similar reasoning the net energy emitted by the frost is:

$$
\begin{aligned}
& \left(\frac{\delta Q}{\delta V}\right)=2 r^{2} \sigma T^{4}\left\{\left[e^{-r y}+r y \ell_{i}(-r y)\right]\right. \\
& \left.+e^{-r(H-s-y)}+r(H-s-y) \varepsilon_{i}[-r(H-s-y)]\right\}
\end{aligned}
$$

In this analysis the boundary conditions are linearized through the assumption that only small changes from the steady state may occur. Suppose that the zero time temperatures are given by $T_{0}(y)$ where

$$
\left|T_{0}(0)-T_{0}(H)\right| \ll T_{0}(y)
$$

Then define $\theta$ such that $T(y, t)=T_{0}(y)[1+\theta(y, t)]$. Then at the exterior interface, $\mathrm{y}=\mathrm{H}$,

$$
k\left(\frac{\partial T}{\partial y}\right)=q=k T_{0}\left(\frac{\partial \theta}{\partial y}\right)+k \frac{\partial T_{0}}{\partial y}(1+\theta) \approx k T_{0}\left(\frac{\partial \theta}{\partial y}\right)+k\left(\frac{\partial T_{0}}{\partial y}\right)
$$

for $\theta \ll 1$. On the other hand, the heat transfer at the interface is

$$
q(T)=q\left(T_{0}\right)+\left(\frac{\partial q}{\partial T}\right)_{T_{0}} T_{0} \theta
$$

The assumption of steady-state at time zero implies that $q\left(T_{0}\right)=k\left(\frac{\partial T_{0}}{\partial y}\right)$; and therefore that

$$
k T_{0}\left(\frac{\partial \theta}{\partial y}\right)=\left(\frac{\partial q}{\partial T}\right)_{T_{0}} T_{0} \theta
$$

The heat equation is put in its final form by substituting $\xi \equiv \gamma(H-s-y)$; $\mathrm{T} \equiv \mathrm{T}_{\mathrm{o}}+\mathrm{T}_{\mathrm{o}} \theta ; \tau \equiv \frac{k \gamma_{\mathrm{a}}^{2_{\mathrm{t}}}}{\rho \mathrm{c}_{\mathrm{p}}} ; \mathrm{h} \equiv \gamma_{\mathrm{a}} \mathrm{H} ; \sigma \equiv \gamma \mathrm{S} . \quad$ (Note that from here on $\mathrm{T}_{\mathrm{o}}(\mathrm{y})$ is assumed constant.) The equation is 


$$
\begin{aligned}
\frac{\partial \theta}{\partial \tau}-\dot{\sigma}\left(\frac{\partial \theta}{\partial \xi}\right)=\frac{\partial^{2} \theta}{\partial \xi^{2}}+ & 2 Q_{E X T} F(\xi)+2 \rho_{23} Q_{E X T} F(h) F(h-\sigma-\xi)-2 Q_{E M} \theta[F(\xi)+F(h-\sigma-\xi)] \\
& +2 \rho_{23} Q_{E M} \theta[1-F(h-\sigma)] F(h-\sigma-\xi)
\end{aligned}
$$

subject to the boundary conditions

$$
\theta(\mathrm{y}, 0)=0 ; \theta(h, \tau)=0 ; \quad \frac{\partial \theta}{\partial \xi}-\mathrm{h} \theta=0 \text { at } \mathrm{y}=0 \text { for all } \tau \text {. }
$$

The heat equation includes the effect of radiation reflecting from the substrate back through the frost.

The full problem requires a machine solution since transform methods won't simplify the equation with mixed derivatives and variable coefficients.

One particular result of the machine solution was that the sublimed depth, o. was much less than the original thickness, $R$, (i.e., $\sigma \ll<$ ) for all times considered. If $\sigma$ is neglected in the radiation terms, then equation ( 6 ) has a closed form, steady state solution.

\section{DISCUSSION OF RESULTS}

These numerical results describe an $\mathrm{H}_{2} \mathrm{O}$ deposit exposed to $290^{\circ} \mathrm{K}$ blackbody radiation, $-\mathrm{e} . \mathrm{g}$. an interior shadow shield. The spectrum of the incoming radiation peaks at $10 \mu$ where water-ice begins a strong continuous absorption band according to Kislovskif (13). Table I gives the values of the physical properties of ice used in the calculation.

Figure 5 presents the temperature profile through the frost for three values of frost optical thickness. These are not steady-state temperature profiles but are long-time or quasi-steady profiles. A truly steady-state cannot occur because the outer surface of the frost continues to sublime. For the thinnest layer $(h=1 / 8)$, the profile has a fairly uniform curvature indicating that absorption takes place over the whole thickness. For the thickest layer 
$(h=4)$, the profile is rather sharply curved, then soon becomes linear. This indicates that absorption is limited to the outer ports of the layer which in turn conducts heat to the inner layers and the cryo-reservoir. Further, the slope at the vacuum-frost interface shows that some mass transfer takes place. In addition to the quasi-steady heat transport, there is also a transient, heat storage effect. Figure 6 shows the outside surface temperature of the frost as a function of frost optical thickness. The increase in surface temperature is explained as follows: as the frost thickness increases the energy absorbed increases up to a limiting value; the frost conductivity limits the amount of heat conducted directly to the substrate; in this analysis, the heat lost by sublimation was made proportional to the outside surface temperature. The outside surface temperature therefore adjusts itself to balance the heat absorbed with that lost by conduction and mass transfer. The ablation rate is small because of the low heat flux and the high heat of sublimation. Figure 7 presents the total heat flux to the cryogen by conduction and transmission. Again, these are not steady-stage values; however, these values should be close to the steady-state. In all cases considered, the frost increases the flux to the cryogen over the value for the bare, reflective surface. The peak flux to the substrate seems to occur for moderately thick frosts, around. $\mathrm{h}=1$; in which case the balance between heat directly transmitted and heat absorbed then conducted is apparently optimum. The same increase in flux occurs for less reflective substrates, say $\rho_{23}=0.50$ (14). So that, in some cases, a very thick frost could lead to reduced flux to the cryogen, compared to the bare-wall flux.

In order to gain some perspective and to view this work in the context of previously reported work, I compare the predicted absorptance with Caren's 
(et al) data [2] for an $\mathrm{H}_{2} \mathrm{O}$ deposit on an $\mathrm{IN}_{2}$ reservoir. They reckoned the absorptance as the ratio of the boil-off heat flux to the energy into their. $300^{\circ} \mathrm{K}$ heater. The solid curve in figure eight is the function $\left(1-\rho_{12}\right)$

$\left[1-\rho_{23} F^{2}(h)\right]$. This function gives all the heat which enters the frost and does not re-emerge. The three sets of absorptance values are not close together. However for small deposit thickness the comparison is good. First off, the optical constants used in this theory were evaluated at $263^{\circ} \mathrm{K}$ whereas the experiments were performed at $77^{\circ} \mathrm{K}$. Secondly, boil-off heat flux measurements themselves are not accurate at low heat fluxes. Thirdly, there was no objective way to estimate the thermal conductance of the void filled deposite layer. In light of these difficulties, the comparison of theory and data is reasonably good.

\section{SUMMARY AND CONCLUDING REMARKS}

This paper began with a survey of current interest in radiative properties of solid condensed gases. The purpose of the survey was to motivate the present analysis and to give a basis for the particular configuration studied here. In the analysis, I postulated that the basis of the energy transport was the conversion of radiant energy to thermal energy. Indeed, the radiation terms enter the heat equation as distributed source terms, - positive for absorption, negative for emission. The results for the temperature profile indicate the following: the frost's temperature rises to the point where mass transfer and conduction to the substrate combine to balance the energy absorbed. Finally, the total heat transfer to the cryogen and the frost were calculated. Comparison of the present theory with published data was reasonably good.

Areas for extending this work are numerous and obvious. First, determination of accurate optical constant data at low temperature is a prime necessity: At 
the Lewis Research Center there is a program to grow deposits on transparent substrates. Then absorptance and reflectance data will be taken. Secondly, the physical nature of the deposits must be determined. Hallett and Mason, (10), have shown that the crystal growth habit can change dramatically depending as whether or not impurities are present in the chamber. Thus a lot of the data on deposits grown in diffusion pumped vacua are questionable. Cryosorption pumping is a necessity. Further, some estimate of the fraction of void volume must be made. Jo R. Howell and $I$ are beginning a Monte-Carlo analysis to include scattering from a random distribution of voids (scattering centers). In lieu of data on void volume, we can only do a parametric analysis. These are only a few of the many areas where fruitful results can be obtained in the study of cryogenic condensates.

SYMBOLS

\footnotetext{
$C_{p} \quad$ specific heat

F intensity diminution function

G absorptance function

H frost thickness

I frost optical thickness, $\alpha H$

$\bar{I}$ heat transfer coefficient

k thermal conductivity

$I_{s}$ heat of sublimation

m sublimation mass flow rate

QHXT external dimensionless heat flux $\frac{\left(1-\rho_{12}\right) \sigma T_{B B} 4}{k r T_{C}}$

$Q_{E M}$ dimensionless emitted flux $\frac{4 n^{2} \sigma T_{c}^{4}}{k r \cdot T_{c}}$

s sublimed thickness

T temperature
} 


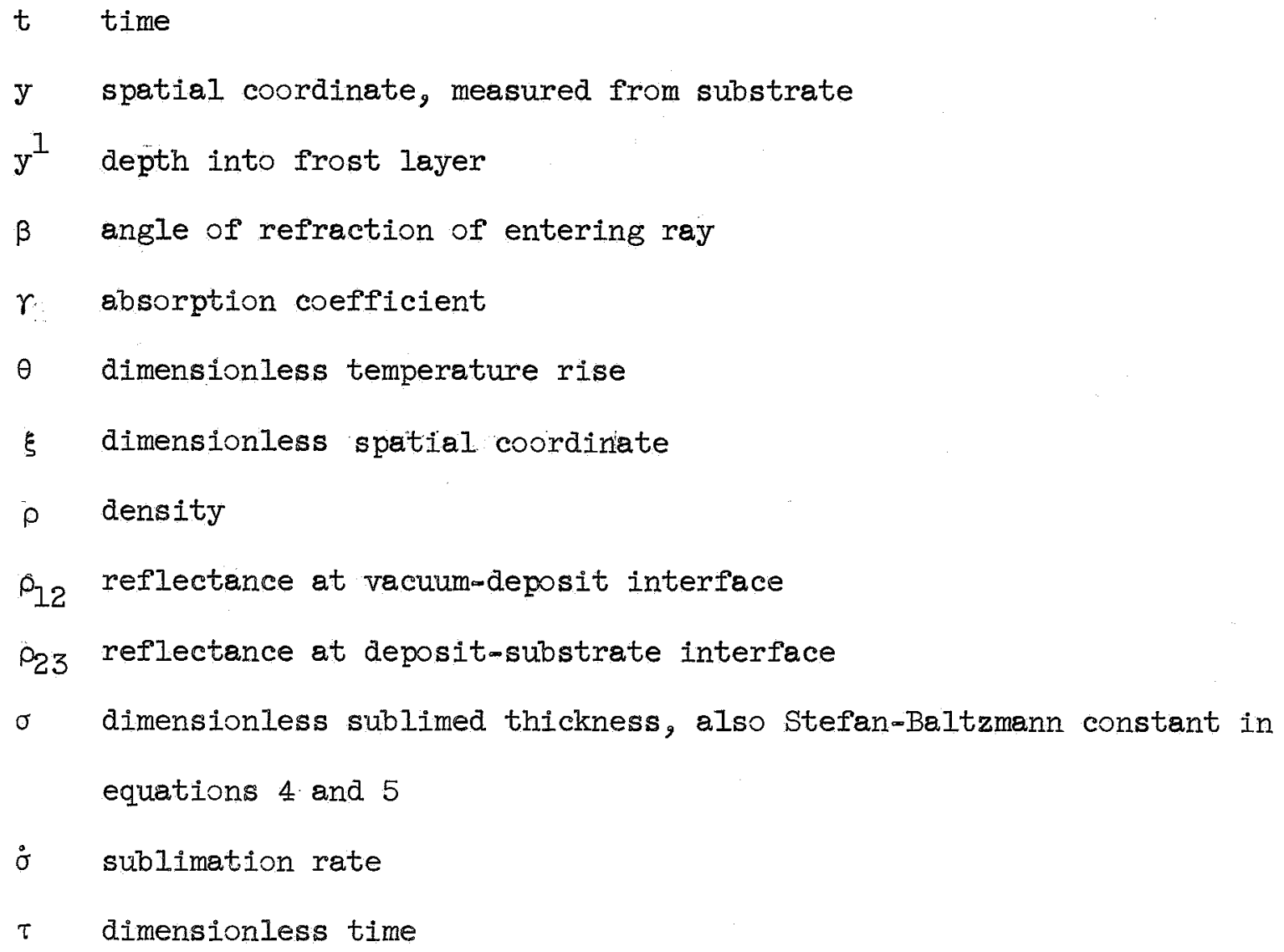

I. Cunningham, T. M., Jr。; and Young, R. I.: The Radiative Properties of Carbon Dioxide Cryodeposits at $77^{\circ} \mathrm{K}$. Rep. No. AECD-TDR-62-165, ARO Inc., Dec. 1962.

2. Caren, R. P.; Gilcrest, A. S.; and Zierman, C. A.: Thermal Absorptances of Cryodeposits for Solar and $290^{\circ} \mathrm{K}$ Blackbody Sources. Advances in Cryogenic Engineering, vol. 9, K. D. Timmerhaus, ed., 1964, Plenum Press, pp. $457-463$.

3. Anon.: Results of the First U. S. Manned Orbital Space Flight, February 20, 1962, NASA, Manned Spacecraft Center, 1962. 
4. Carpenter, M. S.: Pilot's Flight Report. Results of the Second U. S. Manned Orbital Space Flight, May 24, 1962. NASA SP-6, 1962, pp. 69-75.

5. Anon.: Mercury Project Summary Including Results of the Fourth Manned Orbital Flight, May 15 and 16, 1963. NASA SP-45, 1963.

6. Rice, F. O.: The Chemistry of Jupiter. Scientific American, 194, No. 6, June $1956(119-128)$.

7. Herzfeld, C. M.; and Broida, H. P.: Interpretation of Spectra of Atoms and Molecules in Solid Nitrogen Condensed at $4.2^{\circ} \mathrm{K}$. Phys. Rev., 101, No. 2, Jan. 15, $1956(606-611)$.

8. Bass, A. M. ; and Broida, H. P.: Spectra Emitted from Solid Nitrogen Condensed at $4.2^{\circ} \mathrm{K}$ from a Gas Discharge. Phys. Rev., 101, No. 6, Mar. 15, $1956(1740-1747)$.

9. Gardon, R.: The Emissivity of Transparent Materials. J. Am. Cer. Soc., 39, No. 8, Aug。 1956 (278-287).

10. Hallett, J.; and Mason, B. J.: The Influence of Temperature and Supersaturm ation on the Habit of Ice Crystals Grown from the Vapour. Proc. Roy. Soc. (Iondon), Ser. A, 247, No. 1251, Oct. 21, $1958(440-453)$.

11. Keegan, H. J.; and Weidner, V. R.: Infrared Spectral Reflectance of Frost. J. Opt. Soc. Am., 56, No. 4, Apr. 1966 (523-524).

12. Dawson, J. P.; McCulloch, B. A.; Wood, B. E.; Birkebak, R.: Thermal Radiative Properties of Carbon Dioxide Cryodeposits. Presented at the Sixth Annüal Symposium on Space Environmental Simulation, St. Iouis, Mo., May 17-18, 1965. (Available from DDC as AD-465701.) 
13. Alkezweeny, A. J.; and Hobbs, P. V.: The Reflection Spectrum of Ice in the Near Infra-Red. J. Geophys. Res., 71, No. 4, Feb. 15, 1966 (1083-1086)。

14. Kislovskii, I. D.: Optical Characteristics of Water and Ice in the Infrared and Radiowave Regions of the Spectrum. Optics and Spectroscopy, 1, No. 3, Sept. $1959(201-205)$.

15. McConnelI, D. G.: Radiant Energy Transport Within Cryogenic Condensates. Presented at Annula Meeting and Equipment Exposition of the Institute of Environmental Sciences, San Diego, Calif., Apr。11-13, 1966.

TABIE I. - PHYSICAL PROPERTIES OF WATER CRYODEPOSIT

\begin{tabular}{|c|c|}
\hline Property & Value \\
\hline Density of ice & $0.917 \mathrm{~g} / \mathrm{cu} \mathrm{cm}$ \\
\hline Heat of sublimation & $3050 \mathrm{~J} / \mathrm{g}$ \\
\hline Specific heat & $0.697 \mathrm{~J} /(\mathrm{g})\left(\mathrm{O}_{\mathrm{K}}\right)$ \\
\hline Thermal conductivity & $0.078 \mathrm{~J} /(\mathrm{cm})(\mathrm{sec})\left({ }^{\circ} \mathrm{K}\right)$ \\
\hline $\begin{array}{l}\text { Absorption coefficient for } \\
\text { solar radiation }\end{array}$ & $0.0305 / \mu$ \\
\hline $\begin{array}{l}\text { Absoprtion coefficient for } \\
290^{\circ} \mathrm{K} \text { blackbody }\end{array}$ & $0.1578 / \mu$ \\
\hline $\begin{array}{l}\text { Absorption coefficient for } \\
77^{\circ} \mathrm{K} \text { blackbody }\end{array}$ & $0.0640 / \mu$ \\
\hline Emission for $250^{\circ} \mathrm{K}$ case & $0.1578 / \mu$ \\
\hline
\end{tabular}



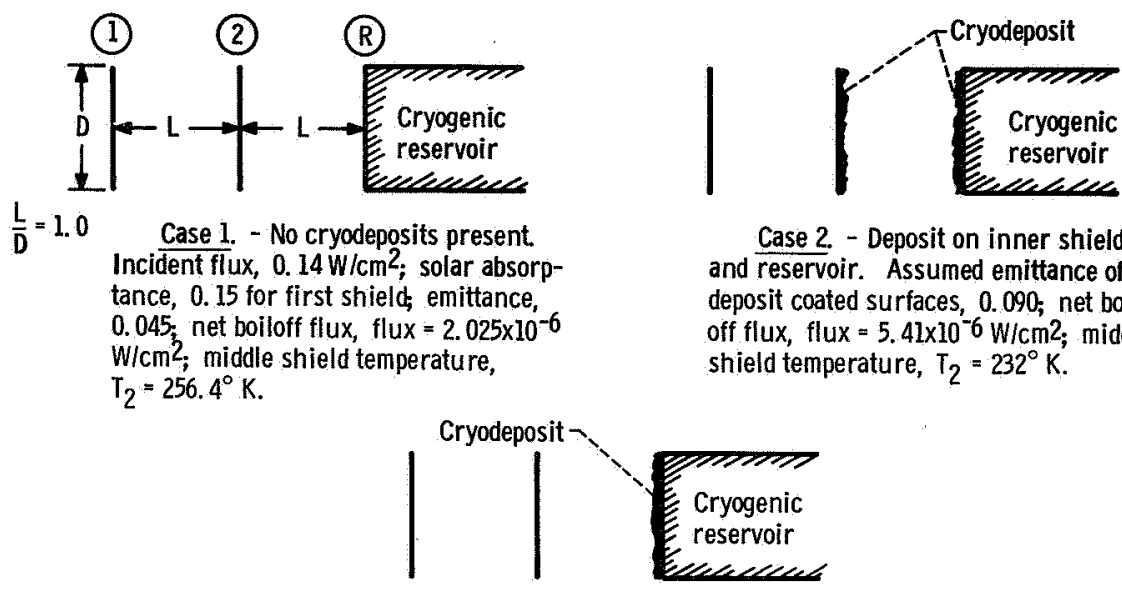

Case 2. - Deposit on inner shield reservoir. Assumed emittance of deposit coated surfaces, 0. 090, net boiloff flux, flux $=5.41 \times 10^{-6} \mathrm{~W} / \mathrm{cm}^{2}$; middle 0.045 . net boiloff flux, flux $=2.025 \times 10^{-6}$ $W / \mathrm{cm}^{2}$; middle shield temperature,

Case 3. - Deposit only on reservoir. Assumed reservoir emittance, 0.090 ; net boiloff flux, flux $=4.04 \times 10^{-6} \mathrm{~W} / \mathrm{cm} 2$. middle shield temperature, $T_{2}=256.4^{\circ} \mathrm{K}$.

Figure 1. - Effect of cryodeposition on shadow shields.

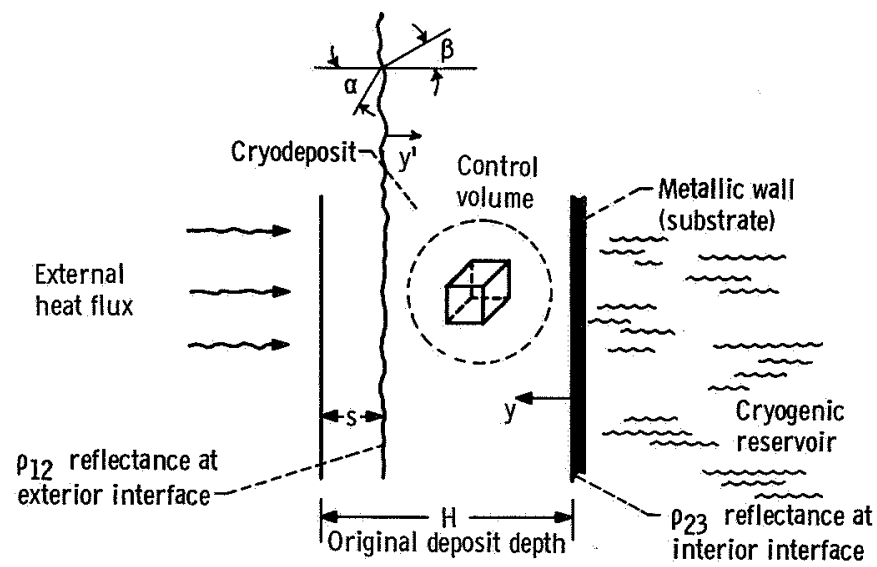

Figure 2. - Configuration analyzed. 




Figure 3. - Ice crystals. 


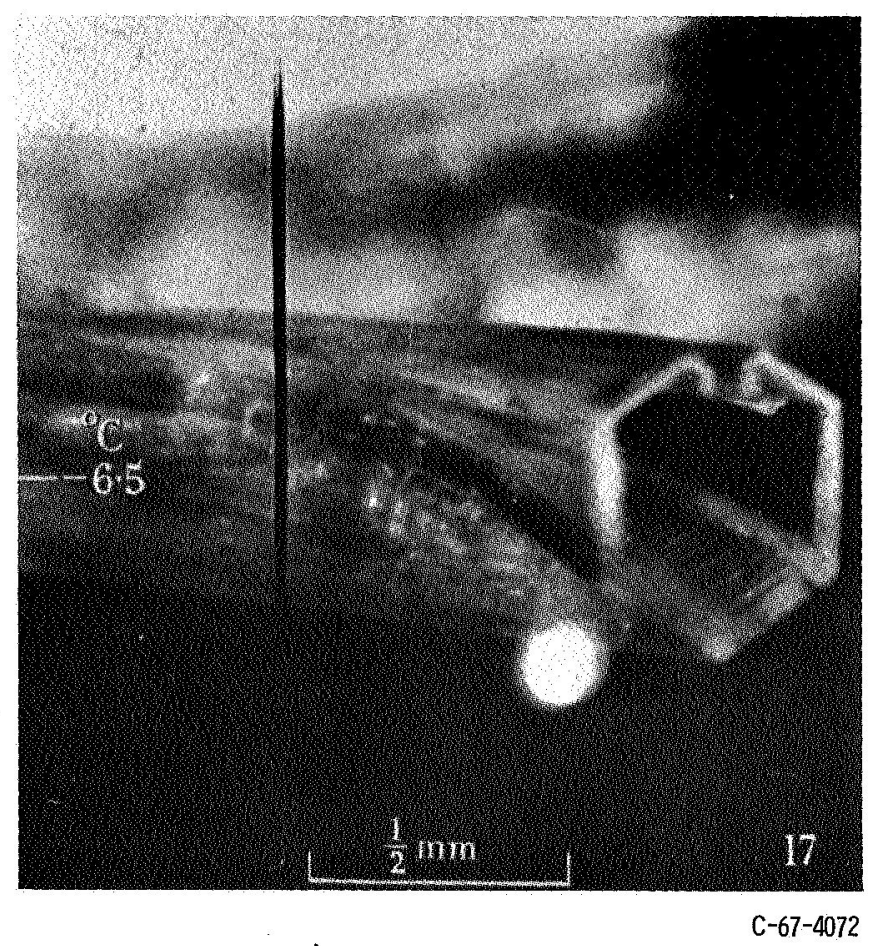

Figure 4. - Ice crystals.

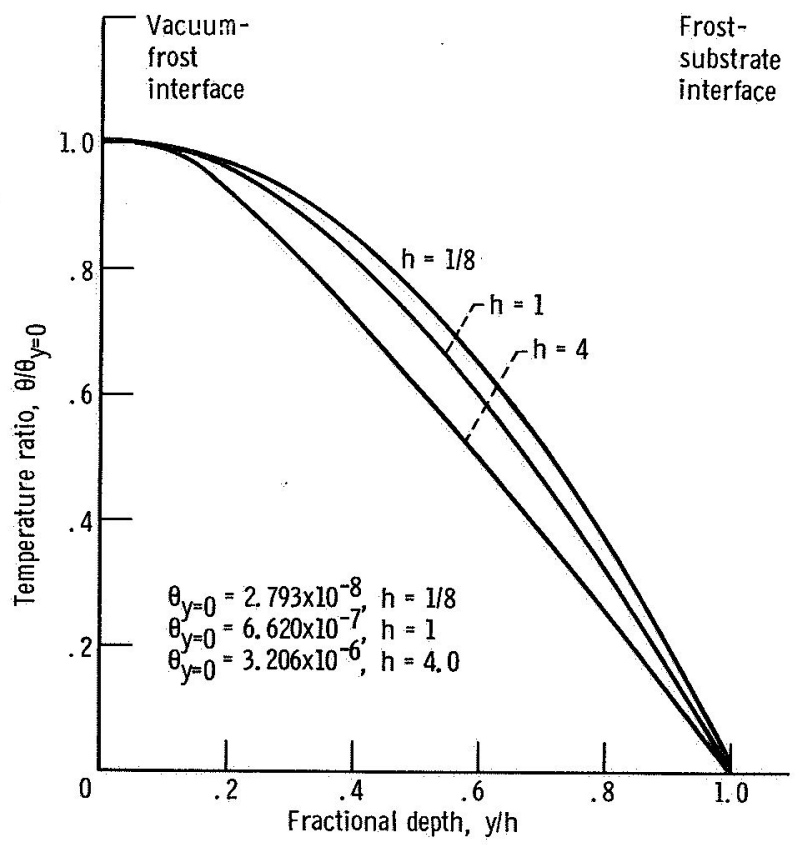

Figure 5. - Temperature profile through deposit layer, $t=32.0$. 


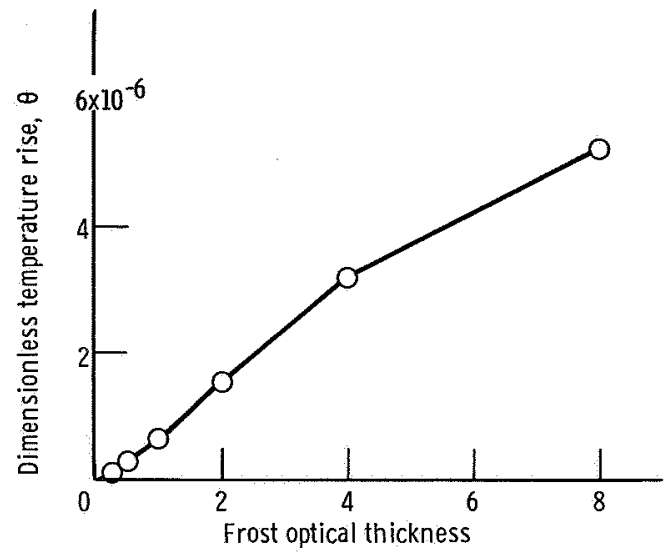

Figure 6. - Temperature rise of vacuum-frost interface.

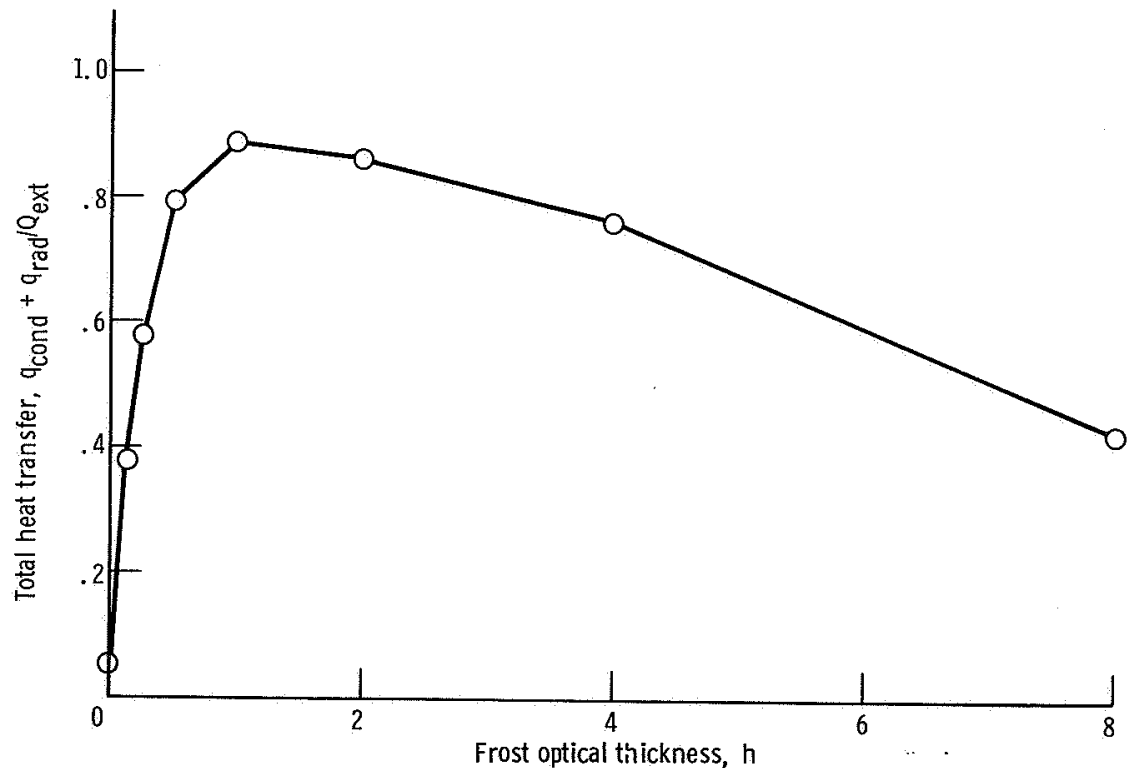

Figure 7. - Total heat transfer through deposit, $\tau=32, p_{23}=0.95$. 


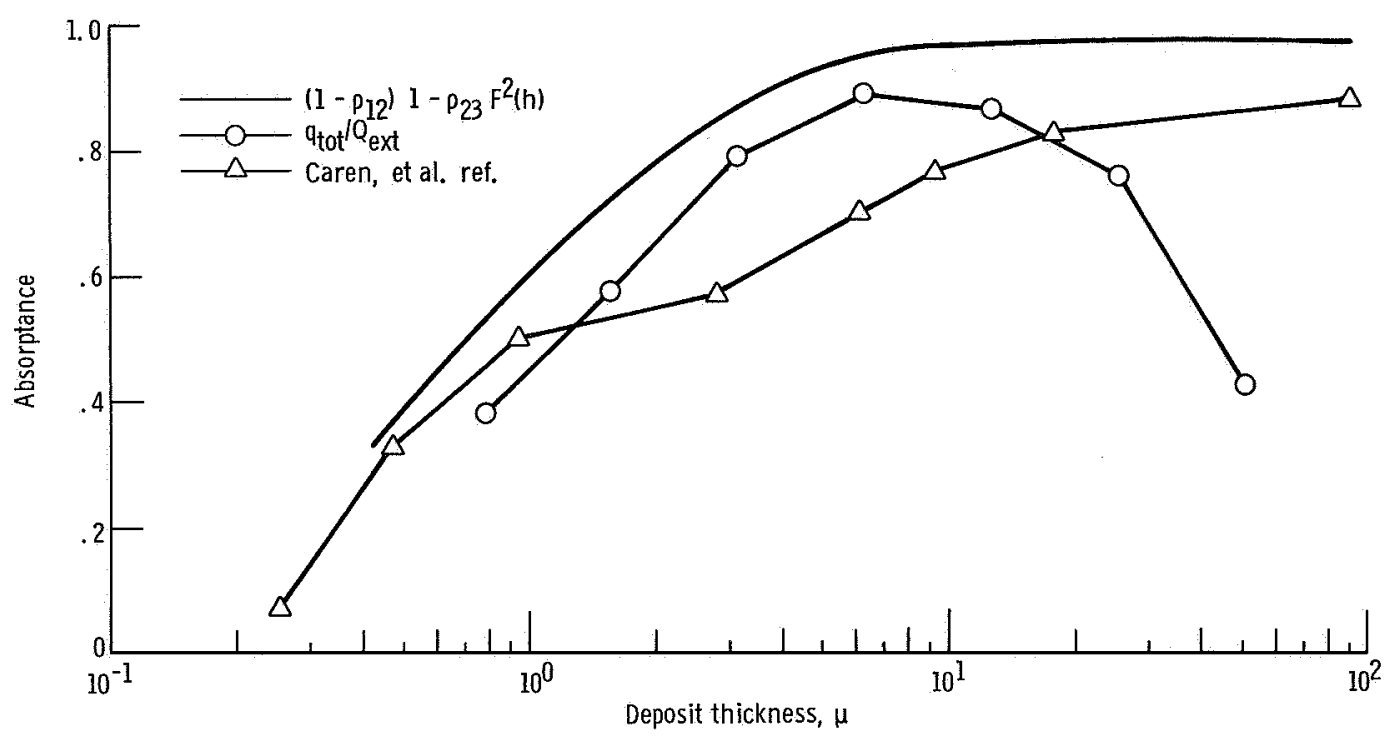

Figure 8. - Comparison of experimental absorptance data with present theory. 